\title{
Determination of blood oxygenation in the brain by time-resolved reflectance spectroscopy: influence of the skin, skull, and meninges
}

Hanli Liu, Andreas H. Hielscher, Bertrand Beauvoit, Lihong V. Wang, Steven L. Jacques, et al.

Hanli Liu, Andreas H. Hielscher, Bertrand Beauvoit, Lihong V. Wang, Steven L. Jacques, Frank K. Tittel, Britton Chance, "Determination of blood oxygenation in the brain by time-resolved reflectance spectroscopy: influence of the skin, skull, and meninges," Proc. SPIE 2136, Biochemical Diagnostic Instrumentation, (21 July 1994); doi: 10.1117/12.180783 


\title{
Determination of the blood oxygenation in the brain \\ by time resolved reflectance spectroscopy (II): \\ Contribution of vascular absorption and tissue background absorption
}

\author{
Hanli Liu ${ }^{1}$, Andreas H. Hielscher ${ }^{2,3}$, Bertrand Beauvoit ${ }^{1}$, Lihong Wang ${ }^{2}$, \\ Steven L. Jacques ${ }^{2}$, Frank K. Tittel ${ }^{3}$, and Britton Chance ${ }^{1}$ \\ 1 University of Pennsylvania \\ Department of Biochemistry and Biophysics \\ Philadelphia, PA 19104-6089 \\ 2 University of Texas, M.D. Anderson Cancer Center \\ Laser Biology Research Laboratory \\ Houston, TX 77030 \\ 3 Rice University \\ Department of Electrical and Computer Engineering \\ Houston, TX 77251-1892
}

\begin{abstract}
The use of near infrared light for the determination of blood oxygenation in the brain has been of great interest over the last years. However, little attention has been paid to the fact that the states of blood oxygenation in arteries, veins, and capillaries differ substantially. An understanding of light absorption by cerebral blood in various blood vessels embedded in the brain tissue is essential for the interpretation of measured brain oxygenation.

In this study, Monte Carlo simulations for a heterogeneous system were conducted, and near infrared time-resolved reflectance measurements were performed on a heterogeneous tissue phantom model. The model was made of a solid polyester resin, which simulates the tissue background. A network of tubes was distributed uniformly through the resin to simulate the blood vessels. The time-resolved reflectance spectra were taken with different absorbing solutions filled in the network. Based on the simulation and experimental results, we investigated the dependence of the absorption coefficient obtained from the heterogeneous system on the absorption of the actual absorbing solution filled in the tubes. We show that light absorption by the brain should result from the combination of blood and blood-free tissue background. Using multiple wavelengths, we should make the oxygenation determination more accurately.
\end{abstract}

\section{INTRODUCTION}

Near infrared (NIR) techniques, including continuous, pulsed, and amplitude-modulated light spectroscopy, have been developed to monitor the oxygenation of the brain noninvasively.1,2,3,4 In particular, using NIR time-resolved or frequency-resolved spectroscopy has a great advantage in obtaining the oxygenation state of cerebral blood and tissue since these techniques can determine accurate path lengths and absorption coefficients. ${ }^{5}$ However, the brain is a very complex biological organ, consisting of various blood vessels and brain tissue, covered by the skin and skull. The relationship between light absorption and vascular 
hemoglobin concentration can be quite complicated since the biological components of the head have different optical properties. In order to obtain accurate oxygenation values of the brain using the NIR technique, it is necessary to understand the influence of the skin and skull and the contribution of the blood vessels to the brain oxygenation measurement.

Much effort has been made in studying the optical properties of the skull and brain tissues. ${ }^{6,7}$ In the first part of this study, ${ }^{8}$ we showed that the absorption properties of the brain tissue can be determined with time-resolved reflectance spectroscopy through the effect of the skin and skull. It was demonstrated that in layered tissue structures, the outer layers affect only the earlier part of the measured time resolved reflectance, while the later part is dominated by the absorption property of the deeper material. Part I of this study ${ }^{8}$ concludes that one can extract the absorption information deep in the brain by fitting the analytical solution found for the diffusion theory to the tail of the time resolved reflectance.

An accurate value of the absorption coefficient of the brain is prerequisite to obtain a correct oxygenation status. Based on the Beer-Lambert law, the absorption coefficient, $\mu_{\mathrm{a}}$, due to hemoglobin at two wavelengths, $\lambda_{1}$ and $\lambda_{2}$, can be written as

$$
\begin{aligned}
& \mu_{\mathrm{a}}^{\lambda 1}=\varepsilon_{\mathrm{Hb}}^{\lambda 1}[\mathrm{Hb}]+\varepsilon_{\mathrm{HbO}_{2}}^{\lambda 1}\left[\mathrm{HbO}_{2}\right] \\
& \mu_{\mathrm{a}}^{\lambda 2}=\varepsilon_{\mathrm{Hb}}^{\lambda 2}[\mathrm{Hb}]+\varepsilon_{\mathrm{HbO}_{2}}^{\lambda 2}\left[\mathrm{HbO}_{2}\right]
\end{aligned}
$$

where $\varepsilon_{\mathrm{Hb}}^{\lambda}$ and $\varepsilon_{\mathrm{HbO}_{2}}^{\lambda}$ are extinction coefficients $\left(\mathrm{cm}^{-1} \mathrm{mM}^{-1}\right)$ of deoxy- and oxy-hemoglobin, and $[\mathrm{Hb}]$ and $\left[\mathrm{HbO}_{2}\right]$ are concentrations of deoxy- and oxy-hemoglobin. Combining these two equations yields the hemoglobin saturation $\mathrm{SO}_{2}$, as follows:

$$
\mathrm{SO}_{2}=\frac{\left[\mathrm{HbO}_{2}\right]}{\left[\mathrm{HbO}_{2}\right]+[\mathrm{Hb}]}=\frac{\frac{\mu_{\mathrm{a}}^{\lambda 1}}{\mu_{\mathrm{a}}^{\lambda 2}} \varepsilon_{\mathrm{Hb}}^{\lambda 2}-\varepsilon_{\mathrm{Hb}}^{\lambda 1}}{\left(\varepsilon_{\mathrm{HbO}}^{\lambda 1}-\varepsilon_{\mathrm{Hb}}^{\lambda 1}\right)-\frac{\mu_{\mathrm{a}}^{\lambda 1}}{\mu_{\mathrm{a}}^{\lambda 2}}\left(\varepsilon_{\mathrm{HbO}}^{\lambda 2}-\varepsilon_{\mathrm{Hb}}^{\lambda 2}\right)}
$$

This formula is applicable to arterial, venous, or tissue saturation when [Hb] and $\left[\mathrm{HbO}_{2}\right]$ are referred to arterial, venous, or tissue hemoglobin concentrations, respectively. An understanding of what the NIR spectroscopy measures is essential toward developing brain oximetry. It is known that in the wavelength range of 700-900 nm, the absorption coefficient of hemoglobin is much larger than that of tissue or water.9,10 Is it reasonable to ignore tissue background absorption? Does the absorption coefficient obtained from the NIR spectroscopy result from blood only or from a combination of blood in the vessels and background tissue?

In searching for the answers to the above questions, this study was conducted on a heterogeneous model, having a simple vascular structure, with 1) time-resolved Monte Carlo simulation and 2) time-resolved spectroscopy (TRS) in reflectance geometry. Our intention is to quantify the contribution of blood in the blood vessels to brain oxygenation and then to obtain the proper algorithm for determination of the brain hemoglobin saturation from the NIR measurement. 


\section{MONTE CARLO SIMULATIONS}

\section{$\underline{2.1 \text { Simulation models }}$}

The heterogeneous model for the Monte Carlo simulation is shown in Figure 1. Small tubes are distributed uniformly in a large homogenous medium. The absorption and reduced scattering coefficients of the background and the material filled in the tubes are represented by $\mu_{\mathrm{a}}$ (back), $\mu_{\mathrm{s}}^{\prime}\left(\right.$ back), $\mu_{\mathrm{a}}$ (tube), and $\mu_{\mathrm{s}}^{\prime}($ tube), respectively. Since the large background can act as hemoglobin-free tissue, $\mu_{\mathrm{a}}$ (back) is chosen to be relatively small, around $0.05 \mathrm{~cm}^{-1}$. In the simulation, the input parameters are optical parameters, $\mu_{\mathrm{a}}$ (back), $\mu_{\mathrm{s}}{ }^{\prime}($ back $), \mu_{\mathrm{a}}$ (tube), and $\mu_{s}^{\prime}$ (tube), the diameter of the tubes, $d$, and the tube distribution distance, 1 . Thus, the volume ratio of the tubes to the total system is known. The output of the simulation is a time-resolved impulse response, at a chosen source-detector separation, $\rho$. From the simulated data, we can obtain an apparent absorption coefficient for the heterogeneous system, $\mu_{\mathrm{a}}$ (system), based on a diffusion theory fit. ${ }^{8}$

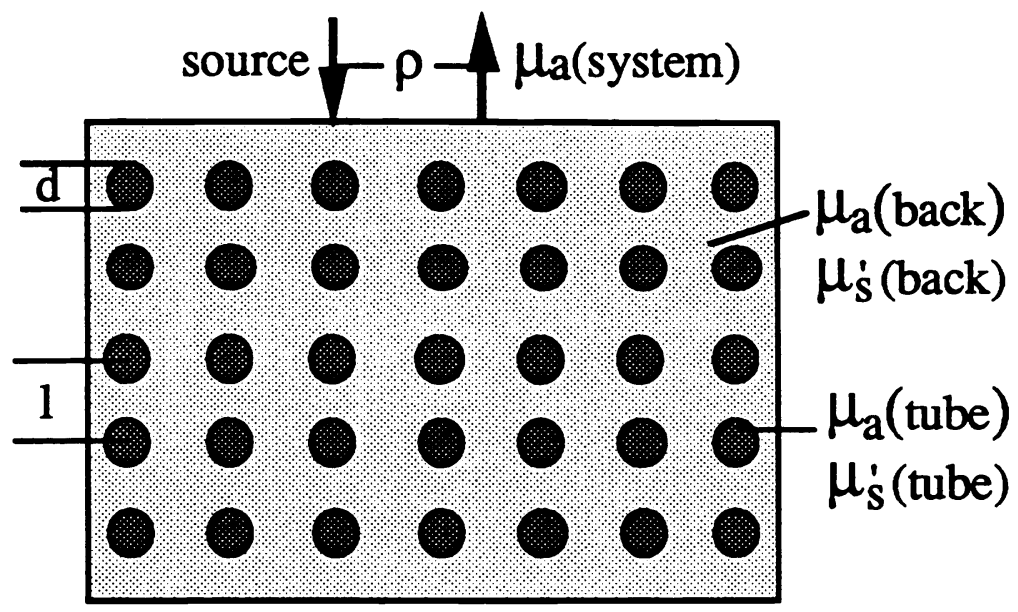

Figure 1. A heterogeneous model for the Monte Carlo simulation. The optical parameters are labeled by $\mu_{\mathrm{a}}$ (back) and $\mu_{\mathrm{s}}{ }^{\prime}$ (back) for the background, $\mu_{\mathrm{a}}$ (tube) and $\mu_{\mathrm{s}}{ }^{\prime}($ tube) for the filling material in the tubes.

In order to study the dependence of the $\mu_{\mathrm{a}}$ (system) on the $\mu_{\mathrm{a}}$ (tube) and $\mu_{\mathrm{a}}$ (back), we assume that the $\mu_{\mathrm{a}}$ (system) is a summation of the absorption coefficients for the different absorbing components contained in the medium, as written below:

$$
\mu_{\mathrm{a}}(\text { system })=\sum_{\mathrm{i}} \mathrm{r}_{\mathrm{i}} \mu_{\mathrm{a}}(\mathrm{i})
$$

where $r_{i}$ is a weighting factor for the $i$ th kind of absorbers in the system. When only one kind of absorber is present in the tubes, then equation (4) becomes

$$
\mu_{\mathrm{a}}(\text { system })=\mathrm{r} \mu_{\mathrm{a}}(\text { tube })+(1-\mathrm{r}) \mu_{\mathrm{a}}(\text { back })
$$

Based on the simulation, we can investigate whether or not the weighting factor, $r$, is related to the volume ratio of the tubes, $\left(\frac{v_{\text {tube }}}{v_{\text {total }}}\right)$. 


\subsection{Simulation results}

The data points (empty circles) shown in figure 2 are obtained from the simulation with the input parameters given in Table 1 . In this case, only one kind of absorber is contained in the system, and $\mu_{s}^{\prime}($ back $)=\mu_{s}^{\prime}($ tube $)$. The tubes occupy $12.6 \%$ of the total volume, and the background makes up $87.4 \%$ of the total volume. Thus, the tube volume ratio is $\mathrm{V}_{\text {tube }} / \mathrm{V}_{\text {total }}=$ 0.126. If it is assumed that $r=V_{\text {tube }} / V_{\text {total }}$, equation (5) gives

$$
\begin{aligned}
\mu_{\mathrm{a}}(\text { system }) & =(0.126) \mu_{\mathrm{a}}(\text { tube })+(0.874) \mu_{\mathrm{a}}(\text { back }) \\
& =(0.126) 0.5+(0.874) 0.05=0.107 \mathrm{~cm}^{-1}
\end{aligned}
$$

On the other hand, using the diffusion theory with the values of $\mu_{\mathrm{a}}$ (system) $=0.107 \mathrm{~cm}^{-1}$ and $\mu_{\mathrm{s}}{ }^{\prime}=10 \mathrm{~cm}^{-1}$ gives rise to the solid curve in figure 2 , which shows a good consistency between the Monte Carlo simulation and diffusion theory.

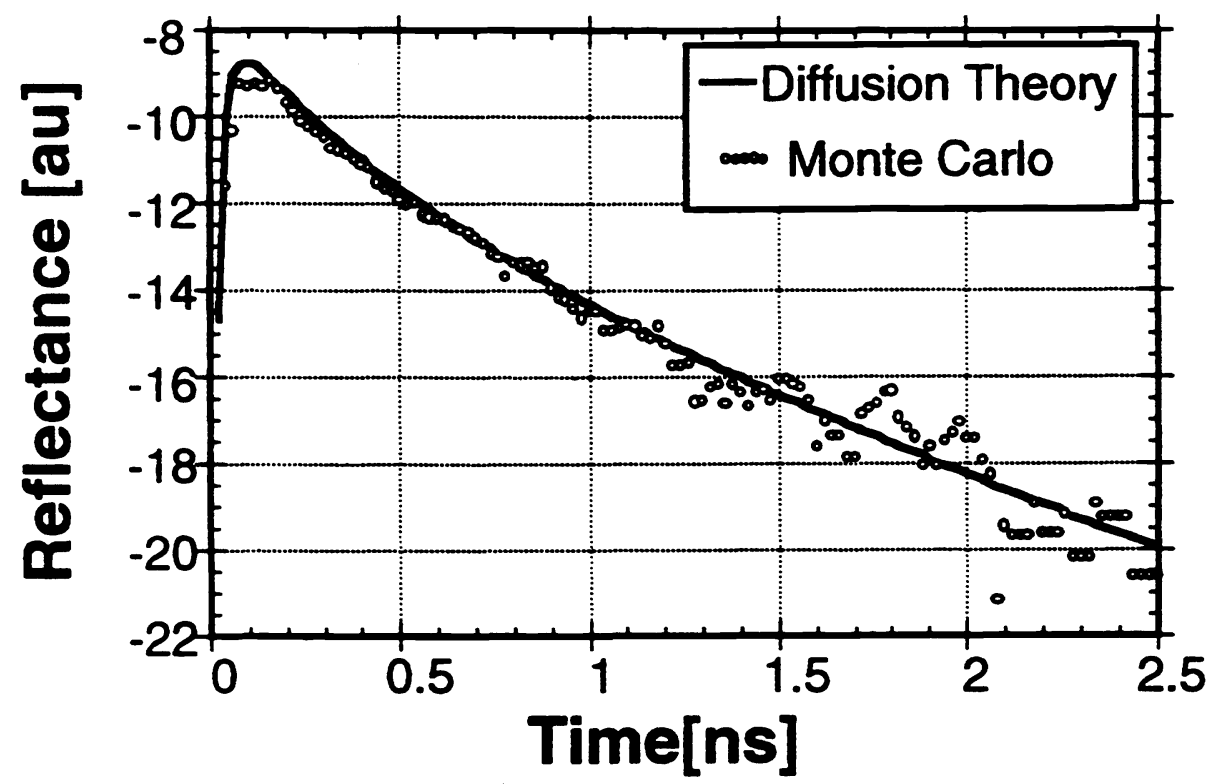

Figure 2. Comparison between the Monte Carlo simulation (empty circles) and the diffusion theory (solid curve) for a one-kind-absorber heterogeneous system.

Next, we changed the system to have two kinds of absorbers contained in the tubes, as shown in figure 3a. The high and low absorbers have the values of $\mu_{\mathrm{a}}$ (tube) equal to $1.0 \mathrm{~cm}^{-1}$ and $0.5 \mathrm{~cm}^{-1}$, respectively, with the same volume ratio of $17.45 \%$. The background has a value of $\mu_{\mathrm{a}}$ (back) $=0.05 \mathrm{~cm}^{-1}$ and takes $65.10 \%$ total volume. The rest input parameters are given in Table 1. In figure $3 \mathrm{~b}$, the circles represent the corresponding simulation results, and the solid curve is calculated based on the diffusion theory using $\mu_{\mathrm{a}}$ (system) $=0.294 \mathrm{~cm}^{-1}$ and $\mu_{\mathrm{s}^{\prime}}=10$ $\mathrm{cm}^{-1}$. 
Table 1. Input Parameters for the Simulation of the heterogeneous system

\begin{tabular}{|c|c|c|}
\hline & $\begin{array}{c}\text { simulation } 1 \\
\text { (figure 2) }\end{array}$ & $\begin{array}{c}\text { simulation 2 } \\
\text { (figure 3) }\end{array}$ \\
\hline $\begin{array}{c}\text { system } \\
\text { condition }\end{array}$ & $\begin{array}{l}\text { one kind } \\
\text { absorber }\end{array}$ & $\begin{array}{l}\text { two kinds } \\
\text { absorber }\end{array}$ \\
\hline tube diameter, $\mathrm{d}, \mathrm{mm}$ & 4 & 4 \\
\hline $\mathrm{s}-\mathrm{d}$ separation, $\rho, \mathrm{mm}$ & 10 & $\overline{12}$ \\
\hline$\mu_{\mathrm{a}}($ back $) \mathrm{cm}^{-1}$ & 0.05 & 0.05 \\
\hline$\mu_{\mathrm{s}}^{\prime}$ (back) $\mathrm{cm}^{-1}$ & 10 & 10 \\
\hline$\mu_{\mathrm{a}}($ tube $) \mathrm{cm}^{-1}$ & 0.5 & 1.0 \\
\hline$\mu_{\mathrm{s}}^{\prime}$ (tube) $\mathrm{cm}^{-1}$ & 10 & 10 \\
\hline tube volume ratio \% & 12.6 & 17.45 \\
\hline$\mu_{\mathrm{a}}$ (system) $\mathrm{cm}^{-1}$ & 0.107 & 0.294 \\
\hline
\end{tabular}

Figure 3(a). Diagram showing two kinds of absorbers distributed in the homogeneous medium. The two kinds of absorbers have the same diameters and volume ratios.

Figure 3(b). A comparison of the simulation results (circles) and the diffusion calculation (solid curve) with $\mu_{\mathrm{a}}=0.294 \mathrm{~cm}^{-1}$ and $\mu_{\mathrm{s}}=10$ $\mathrm{cm}^{-1}$.
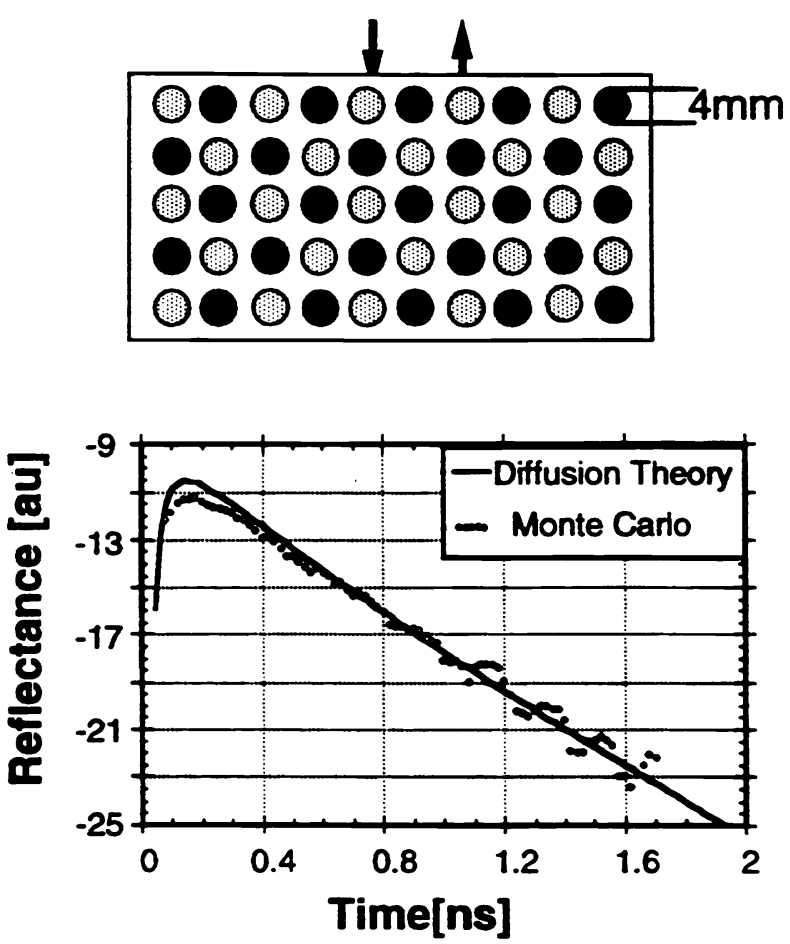

Both figure 2 and figure 3 show that the earlier part of the time dependent simulation result has small deviation from the diffusion theory curve, but that the later part of the profile (after about $0.4 \mathrm{~ns}$ ) gives a good agreement between the simulation and diffusion theory. Based on part I of this study, ${ }^{8}$ we know that the earlier response results from more superficial materials, whereas the later response corresponds to the deeper materials. It is seen that the agreement between the Monte Carlo simulation and diffusion theory, using the $\mu_{\mathrm{a}}$ (system) value, is still held very well in the later part for this heterogeneous system. These simulation results indicate that the weighting factor, $r$, in equation (5) is equal to the volume ratio of the corresponding distributed absorbers in the system. 


\section{EXPERIMENTAL STUDIES}

\section{$\underline{3.1 \text { Experimental models }}$}

The experimental model is made of a polyester resin, which simulates a low absorbing tissue background. The resin is mixed with a certain concentration of $\mathrm{TiO}_{2}$ for a proper value of the reduced scattering coefficient $\mu_{s}{ }^{\prime}$ (back). ${ }^{11}$ As demonstrated in figure 4, another optically-identical sample is made with a network of small tubes (vertical holes), which simulate blood vessels and can be filled with absorbing solutions. The sample used for this study has values of $\mu_{\mathrm{a}}$ (back) $=0.06 \mathrm{~cm}^{-1}$ and $\mu_{\mathrm{s}}($ back $)=9.2 \mathrm{~cm}^{-1}$. The tubes have $3 \mathrm{~mm}$ diameters and make up $14 \%$ of the entire volume. With the conventional single photon counting system, described elsewhere, ${ }^{12}$ the measurement was performed on the side of the sample with a separation of $3 \mathrm{~cm}$.

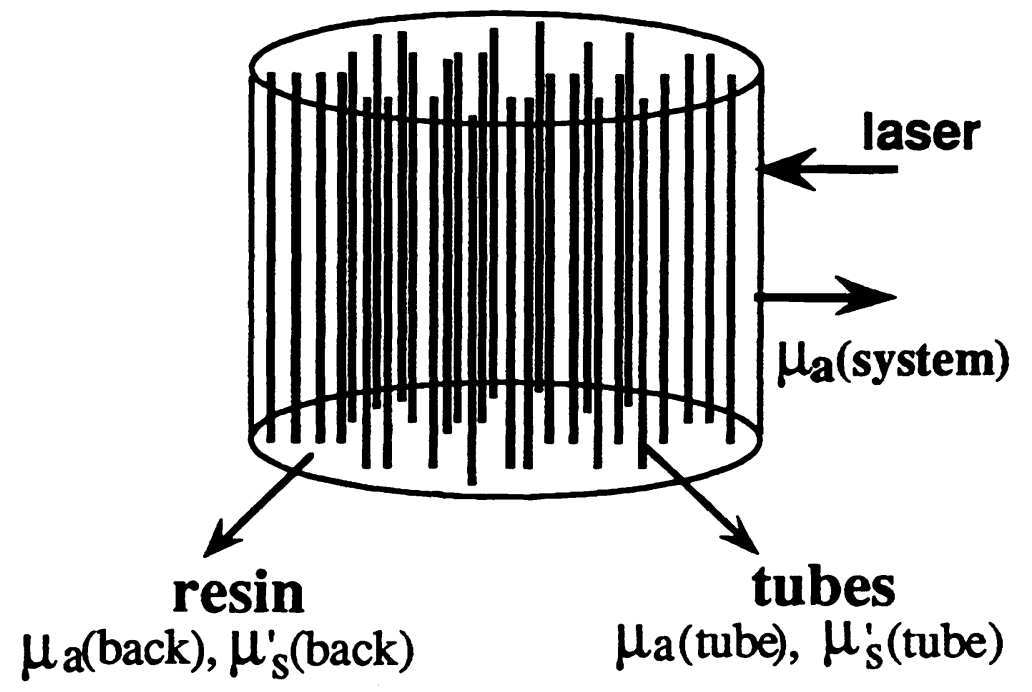

Figure 4. The experimental model made of a polyester resin with many empty tubes simulating the blood vessels. The absorption and reduced scattering coefficients for the filling materials are $\mu_{\mathrm{a}}$ (tube) and $\mu_{\mathrm{s}}^{\prime}($ tube).

\subsection{Experimental results}

A set of TRS measurement was obtained from the resin sample alone, solution alone, and the resin with the solution filled in the holes, respectively. In this case, the solution was $1 \%$ intralipid with a certain concentration of absorbers (india ink), and the reduced scattering coefficients for both the resin and the solution were the same. The results are shown in a normalized $\log 10$ scale (Figure 5). By fitting the spectra with the diffusion theory, we obtained $\mu_{\mathrm{a}}$ (back) $=0.06 \mathrm{~cm}^{-1}$ for the resin only, $\mu_{\mathrm{a}}($ tube $)=0.322 \mathrm{~cm}^{-1}$ for the solution only, and $\mu_{\mathrm{a}}($ system $)=0.11 \mathrm{~cm}^{-1}$ for the combined heterogeneous system. 


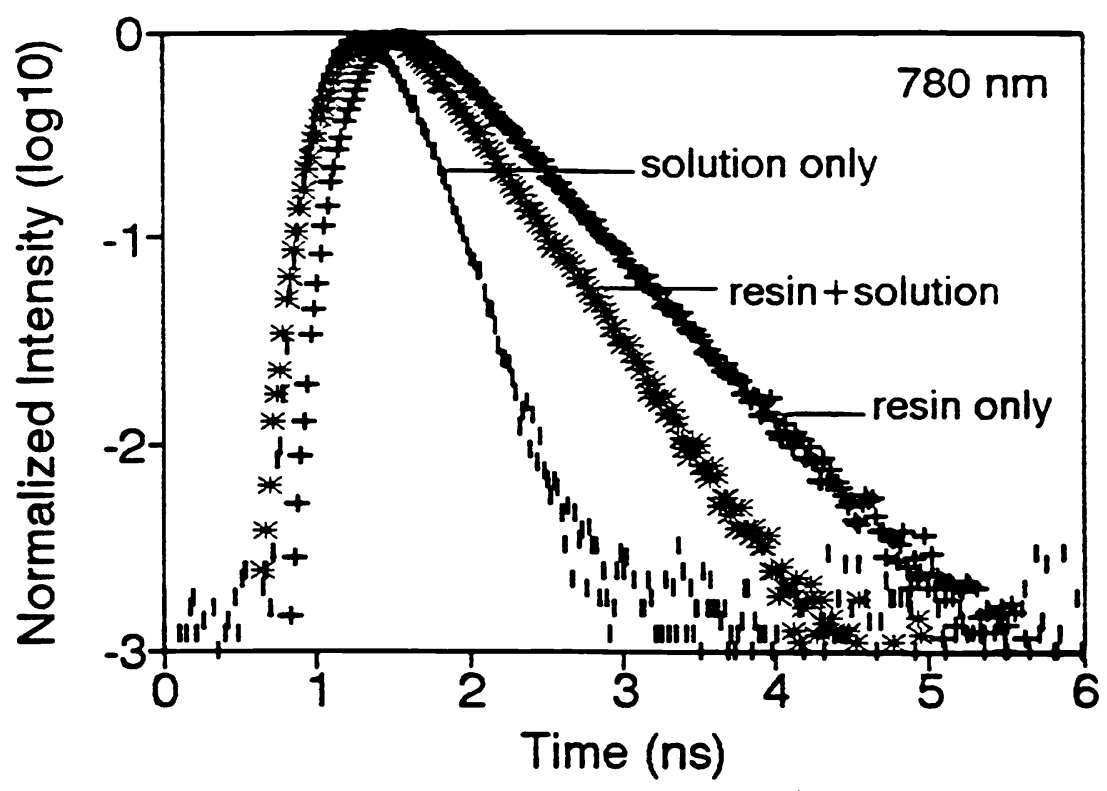

Figure 5. Time resolved reflectance spectra measured on the model system with the 50-ps, $780 \mathrm{~nm}$ light pulses. The resin sample (plus) has a low absorption, intralipid solution with ink (vertical line) has a high absorption, and the resin with the solution filled in the holes (asterisk) has an absorption in between. The source-detector separation is $3 \mathrm{~cm}$.

An increase in absorber concentration in the solution leads to increases in the values of $\mu_{\mathrm{a}}$ (tube) and thus $\mu_{\mathrm{a}}$ (system). A set of $\mu_{\mathrm{a}}$ (tube) and $\mu_{\mathrm{a}}$ (system) were measured on the same resin sample as a function of absorber concentrations, using $670 \mathrm{~nm}$ light pulses. In this case, liquid absorbers in the tubes were methemoglobin solutions, which were made from the hemoglobin (Sigma, H2625) totally converted to methemoglobin by adding potassium ferricyanide. $0.5 \%$ intralipid was used to dilute the methemoglobin solution. Figure 6 shows that $\mu_{\mathrm{a}}$ (tube) and $\mu_{\mathrm{a}}$ (system) are proportional linearly to the absorber concentration, but the slope for the solution only is much larger than that for the combined system. These two linear lines can be written as

$$
\begin{aligned}
& \mu_{\mathrm{a}}(\text { system })=\mathrm{k}_{1} \mathrm{x}+\mathrm{b}=1.210^{-4} \mathrm{x}+0.07 \\
& \mu_{\mathrm{a}}(\text { tube })=\mathrm{k}_{2} \mathrm{x}+\mathrm{c}=810^{-4} \mathrm{x}+0.0027
\end{aligned}
$$

where $\mathrm{x}$ is the absorber concentration in the solution. Then, combining these two equations leads to a relationship between $\mu_{\mathrm{a}}$ (system) and $\mu_{\mathrm{a}}$ (tube), as follows:

$$
\mu_{\mathrm{a}}(\text { system })=\mathrm{k}_{1} / \mathrm{k}_{2} \mu_{\mathrm{a}} \text { (tube) }+ \text { const. }
$$

By comparing equation (6) with equation (5), one recognizes that factor $k_{1} / k_{2}$ in equation (6) is corresponding to the weighting factor, $r$. The data from figure 6 gives $k_{1} / k_{2}$ equal to $15 \%$, which is very close to the actual tube volume ratio, $14 \%$. This result indicates that the weighting factor and the volume ratio are identical. 
Figure 6. Absorption coefficients of a met-hemoglobin solution (solid square) and of the heterogeneous system (empty square) as a function of met-hemoglobin concentration. The linear lines are the least square fit.

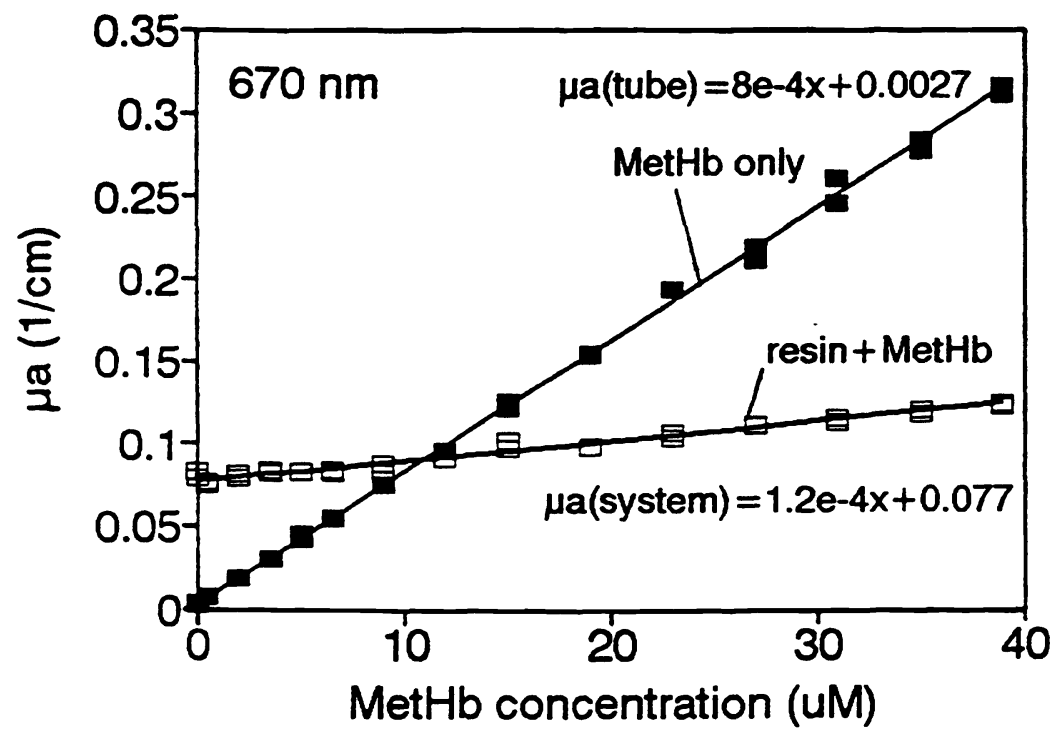

It seems that the simulation and experimental results support that when the difference in absorption between the background and absorbers is not larger than 10-15 times, the value of $\mu_{\mathrm{a}}$ (system) for a heterogeneous system containing distributed absorbers is proportional to the $\mu_{\mathrm{a}}$ (absorber) and the absorber volume ratios. However, it is known that the absorption coefficient of pure blood is much higher than that of the tissue. By using the Beer-Lambert law, we can estimate the $\mu_{\mathrm{a}}$ value (in $\mathrm{ln}$ ) of human blood at $780 \mathrm{~nm}$ by

$$
\mu_{\mathrm{a}}{ }^{780}=[\mathrm{c}] \varepsilon^{780}=8 \mathrm{mM} 0.46 \mathrm{~cm}^{-1} \mathrm{mM}^{-1}=3.68 \mathrm{~cm}^{-1}
$$

where it was assumed that the hemoglobin concentration of the blood is $8 \mathrm{mM}$. The value of $3.68 \mathrm{~cm}^{-1}$ is in agreement with our blood measurements using TRS.

Figure 7. Absorption coefficients of an intralipid-ink solution (solid square) and of the resin model with the solution filled in the tubes (empty square) as a function of ink concentration. Note that there are two straight fitting lines for the combined system.

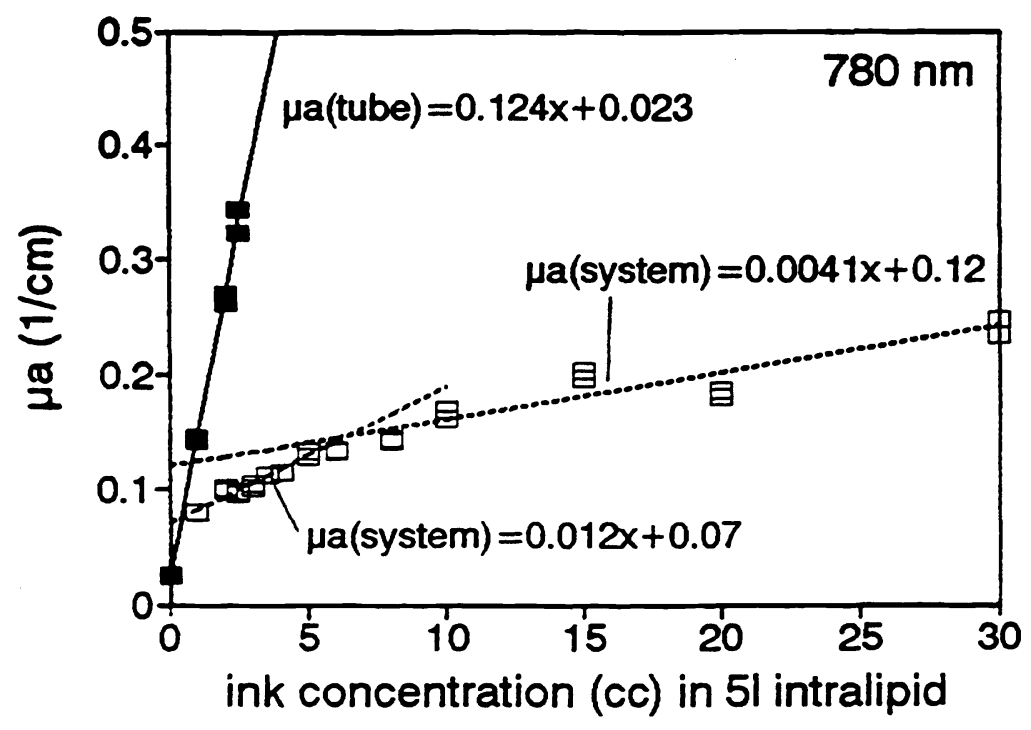


Figure 7 shows the results for the case when the absorption coefficient of the liquid absorbers (ink) in the tubes are much larger than that of the background. when the ink concentration is larger than a certain value, the value of $\mu_{\mathrm{a}}$ (system) becomes insensitive to the absorber concentration, and the slope for the combined system changed from 0.0052 to 0.0018 . Thus, the value of $\mathrm{k} 1 / \mathrm{k} 2$ decreased from 0.1 to 0.03 . This result suggests that when the difference in absorption between the background and absorbers is large ( $\geq 15$ times ), the weighting factor, $r$, is not equal to the volume ratio any more; $r$ becomes much smaller than the volume ratio. The factor $\mathrm{r}$ now can be thought of as a contribution factor to the measurement from the hidden absorbers distributed in a uniform background .

\section{DISCUSSION}

The experimental results shown above may suggest that only $2-3 \%$ of the blood in the blood vessels makes contributions to the measured $\mu_{a}$ by optical non-invasive methods. Possible explanations for this behavior is that photons can not pass through large vessels since the large vessels absorb the light much more than small vessels and tissue background. A hypothesis is that NIR techniques mainly measure capillaries, so that the hemoglobin saturation obtained in the NIR spectroscopy corresponds to the oxygenation of the capillary bed and brain tissue. Further study is needed to prove this hypothesis.

The low absorbing homogenous background may include capillary bed and hemoglobin-free tissue. In order to obtain correct blood oxygenation in the brain, one should thus employ three wavelengths to take into account the background absorption. From equation (5), one has

$$
\left.\mu_{\mathrm{a}}^{\lambda}(\text { system })=r \mu_{\mathrm{a}}^{\lambda} \text { (blood }\right)+(1-\mathrm{r}) \mu_{\mathrm{a}}(\text { tissue })=\mathrm{r} \mu_{\mathrm{a}}(\text { blood })+\alpha
$$

where $\alpha$ is assumed wavelength independent over a small wavelength range. If three wavelengths are used to measure $\mu_{\mathrm{a}}$, equation (7) gives rise to

$$
\begin{aligned}
& \mu_{\mathrm{a}}^{\lambda 1}=\mathrm{r}\left(\varepsilon_{\mathrm{Hb}}^{\lambda 1}[\mathrm{Hb}]+\varepsilon_{\mathrm{HbO}_{2}}^{\lambda 1}\left[\mathrm{HbO}_{2}\right]\right)+\alpha \\
& \mu_{\mathrm{a}}^{\lambda 2}=\mathrm{r}\left(\varepsilon_{\mathrm{Hb}}^{\lambda 2}[\mathrm{Hb}]+\varepsilon_{\mathrm{HbO}_{2}}^{\lambda 2}\left[\mathrm{HbO}_{2}\right]\right)+\alpha \\
& \mu_{\mathrm{a}}^{\lambda 3}=\mathrm{r}\left(\varepsilon_{\mathrm{Hb}}^{\lambda 3}[\mathrm{Hb}]+\varepsilon_{\mathrm{HbO}_{2}}^{\lambda 3}\left[\mathrm{HbO}_{2}\right]\right)+\alpha
\end{aligned}
$$

After solving these equations for $\mathrm{r}[\mathrm{Hb}]$ and $\mathrm{r}\left[\mathrm{HbO}_{2}\right]$, one obtains the hemoglobin saturation as follows:

$$
\begin{gathered}
\mathrm{SO}_{2}=\frac{\mathrm{r}\left[\mathrm{HbO}_{2}\right]}{\mathrm{r}\left[\mathrm{HbO}_{2}\right]+\mathrm{r}[\mathrm{Hb}]}=\frac{\left[\mathrm{HbO}_{2}\right]}{\left[\mathrm{HbO}_{2}\right]+[\mathrm{Hb}]} \\
\mathrm{SO}_{2}=\frac{\beta\left(\varepsilon_{\mathrm{Hb}}^{\lambda 3}-\varepsilon_{\mathrm{Hb}}^{\lambda 2}\right)-\left(\varepsilon_{\mathrm{Hb}}^{\lambda 1}-\varepsilon_{\mathrm{Hb}}^{\lambda 2}\right)}{\left[\left(\varepsilon_{\mathrm{HbO}_{2}}^{\lambda 1}-\varepsilon_{\mathrm{Hb}}^{\lambda 1}\right)-\left(\varepsilon_{\mathrm{HbO}_{2}}^{\lambda 2}-\varepsilon_{\mathrm{Hb}}^{\lambda 2}\right)\right]-\beta\left[\left(\varepsilon_{\mathrm{HbO}_{2}}^{\lambda 3}-\varepsilon_{\mathrm{Hb}}^{\lambda 3}\right)-\left(\varepsilon_{\mathrm{HbO}}^{\lambda 2}-\varepsilon_{\mathrm{Hb}}^{\lambda 2}\right)\right]}
\end{gathered}
$$


where $\beta=\frac{\mu_{a}^{\lambda 1}-\mu_{a}^{\lambda 2}}{\mu_{a}^{\lambda 3}-\mu_{a}^{\lambda 2}}$, and $\mu_{a}^{\lambda 1}, \mu_{a}^{\lambda 2}$, and $\mu_{a}^{\lambda 3}$ can be measured from TRS.

In conclusion, 1) in order to obtain correct blood oxygenation, $\mathrm{Hb}$-free tissue absorption should not be ignored; 2) the use of three wavelengths allows to quantify blood oxygenation quite accurately; 3 ) small vessels and capillary bed may make more contributions to the detected NIR signals; and 4) the absorption coefficient observed from the TRS measurement results from both blood vessels and background tissue, and the relationship between $\mu_{\mathrm{a}}$ (system) observed in TRS and the absorption coefficient of the pure blood is more complex than just a simple volume ratio. This relationship needs further investigation.

\section{REFERENCES}

1 M. Ferrari, E. Zanetti, I. Giannini, G. Sideri, C. Fieschi, and A. Carpi, "Effects of carotid artery compression test on regional cerebral blood volume, haemoglobin oxygen saturation and cytochrome-coxidase redox level in cerebrovascular patients", Adv. Exp. Med. Biol., Vol.200, pp. 213-222, 1986.

2 C. E. Elwell, M. Cope, A. D. Edwards, J. S. Wyatt, and E. O. R. Reynolds, "Measurement of cerebral blood flow in adult humans using near infrared spectroscopy--methodology and possible errors", Adv. Exp. Med. Biol., Vol. 317, pp. 235-245, 1992.

3 David S. Smith, Warren J. Levy, Steve Carter, Nang Wang, Munetaka Haida, and Britton Chance, "Time resolved spectroscopy and the determination of photon scattering, pathlength and brain vascular hemoglobin saturation in a population of normal volunteers", SPIE Proceedings: Photon Migration and Imaging in Random Media and Tissue, Vol. 1888, pp. 511-515, 1993.

4 A. H. Hielscher, F. K. Tittel, and S. L. Jacques, "Non-invasive monitoring of blood oxygenation by phase resolved transmission spectroscopy", SPIE Proceedings: Photon Migration and Imaging in Random Media and Tissue, Vol. 1888, pp. 265-288, 1993.

5 E. M. Sevick, B. Chance, J. Leigh, S. Nioka, and M. Maris, "Quantitation of Time- and FrequencyResolved Optical Spectra for the determination of Tissue Oxygenation", Analytical Biochemistry, Vol. 195, pp. 330-351, 1991.

6 Pieter van der Zee, Matthias Essenpreis, and David T. Delpy, "Optical properties of brain tissue", SPIE Proceedings : Photon Migration and Imaging in Random Media and Tissue, Vol. 1888, pp. 454-465, 1993.

7 M. Firbank, M. Hiraoka, M. Essenpreis, and D. T. Delpy, "Measurement of the optical properties of the skull in the wavelength range 650-950 nm", Phys. Med. Biol., Vol .38, pp. 503-510, 1993.

8 Andreas H. Hielscher, Hanli Liu, Frank K. Tittel, Britton Chance, and Steven L. Jacques, "Determination of the blood oxygenation in the brain by time resolved reflectance spectroscopy", SPIE 2136A-02, in Optical Diagnosis of Blood and Blood Components, presented at Biomedical Optics'94, Los Angeles, CA, January 22-28, 1994. 
9 B.C. Wilson, M.S. Patterson, S.T. Flock, and D.R. Wyman, in Photon Migration in Tissues ed. by B. Chance, Plenum Press, New York, 1989.

10 B.C. Wilson, "Optical Properties of Tissues", in Encyclopedia of Human Biology, Vol. 5, Academic Press, Inc. pp.587, 1991.

11 Michael Firbank, Mutsuhisa Hiraoka, and David T. Delpy, "Development of a stable and reproducilbe tissue equivalent phantom for use in infrared spectroscopy and imaging", SPIE Proceedings: Photon Migration and Imaging in Random Media and Tissue, Vol. 1888, pp. 264-274, 1993.

12 H. Liu, M. Miwa, B. Beauvoit, N.G. Wang, and B. Chance, "Characterization of absorption and scattering properties of small-volume biological samples using time-resolved spectroscopy", Analytical biochemistty, Vol. 213, pp. 378-385, 1993. 